ORIGINAL ARTICLE

\title{
Sublingual immunotherapy in asthma and rhinoconjunctivitis; systematic review of paediatric literature
}

\author{
S Miceli Sopo, M Macchiaiolo, G Zorzi, S Tripodi
}

Arch Dis Child 2004;89:620-624. doi: 10.1136/adc.2003.030411

See end of article for
authors' affiliations
$\ldots \ldots \ldots \ldots \ldots \ldots \ldots \ldots \ldots$
Correspondence to:
Dr S Miceli Sopo,
Department of Pediatric
Science-Università
Cattolica del Sacro Cuore,
Largo A. Gemelli, 8,
00168 Rome, Italy;
stefano.micelisopo@
libero.it
Accepted
17 November 2003

\begin{abstract}
Aims: To evaluate the clinical efficacy of sublingual immunotherapy (SLIT) in respiratory allergy in children. Methods: A systematic literature review was conducted. The search was focused on all the double blind (and double dummy if necessary) studies. Search strategy: Medline, Embase, Cochrane Controlled Trial Register, Abstract of Cochrane Airways Group, hand search, and archives of some SLIT producers. All the selected studies were assessed and evaluated for quality in a standardised independent way.

Results: Eight randomised, double blind, placebo controlled studies on SLIT were selected. Five studies were run with house dust mite (HDM), one with olive pollen, one with wall pellitory (Parietaria) pollen, and one with grass pollen. A quantitative evaluation of the studies was not possible because the outcomes and the results of single studies were presented according to different criteria. Therefore only qualitative analysis was performed. No clinically relevant results were shown, independently from statistical significance, in the use of SLIT for respiratory allergies due to seasonal allergens (olive, wall pellitory, and grass pollens) and, on the whole, for rhinoconjunctivitis due to HDM in children. For mild to moderate persistent asthma due to HDM, statistically significant and low to moderate relevant clinical effects were observed.

Conclusions: SLIT can be currently considered to have low to moderate clinical efficacy in children of at least 4 years of age, monosensitised to HDM, and suffering from mild to moderate persistent asthma. This benefit seems to be adjunctive with respect to the environmental preventive measures against HDM.
\end{abstract}

$\mathrm{R}$ ecently specific immunotherapy (SIT) by the sublingual route (sublingual immunotherapy, SLIT) has been increasing in acceptance in clinical practice, mainly in Central Europe; ${ }^{1}$ it is currently the most used form of specific immunotherapy in children. This is due to its ease of administration and documented safety. ${ }^{2}$ However, there are still doubts in the scientific community about its clinical efficacy. ${ }^{4-8}$

Clinical efficacy of SIT in allergies has been analysed in two systematic reviews, one of which was based only on injected SIT. ${ }^{9}$ The authors of the second systematic review ${ }^{10}$ only analysed the efficacy of SLIT in allergic rhinitis. They found that SLIT is a safe treatment which significantly reduces symptoms and medication requirements in allergic rhinitis in the adult population; but these results could not be confirmed in the paediatric group. In this review, however, one apparently eligible study ${ }^{11}$ was not included, and the results of another, ${ }^{12}$ which was conducted among children, were inexplicably included in the adult population. We therefore decided to perform a new systematic review on the efficacy of SLIT in allergic asthma and rhinoconjunctivitis in children. We posed the following questions:

- Is SLIT effective in reducing symptoms of allergic asthma and/or rhinoconjunctivitis in children?

- Is SLIT capable of reducing the need for rescue and preventive drugs for asthma and/or rhinoconjunctivitis in children?

\section{METHODS}

\section{Objectives of the systematic review}

- To identify all randomised and double blind (and double dummy if necessary) clinical studies on clinical efficacy of SLIT administered according to the swallow or the spit technique in children (aged 0-18 years) suffering from asthma and/or rhinoconjunctivitis due to inhalant allergens.

- To evaluate the methodological quality of the identified studies.

- To estimate the overall efficacy of SLIT on symptoms of asthma and/or rhinoconjunctivitis and on consumption of rescue or preventive drugs from both a qualitative and (if possible) a quantitative point of view.

\section{Search of the literature}

We used the following instruments for the search of the relevant studies:

- The Pubmed search engine to enter the Medline database (search extended to June 2003) using the terms: asthma, wheezing, conjunctivitis, rhin*, hay fever, immunotherapy, desensitisation, hyposensitisation, allergen immunotherapy, sublingual, oral, local.

- The Embase database (search extended to June 2003) using the above terms plus perennial rhinitis, systemic desensitisation, papillary conjunctivitis, school child and pre-school child, oral/sublingual drug administration.

We extended our search for relevant studies looking through or by means of:

- The Cochrane Controlled Trials Register.

- Abstracts of the Cochrane Airways Group.

- References of some reviews published on the subject. ${ }^{4-8}$

- References of the clinical studies identified as relevant.

Abbreviations: HDM, house dust mite; SIT, specific immunotherapy; SLIT, sublingual immunotherapy 


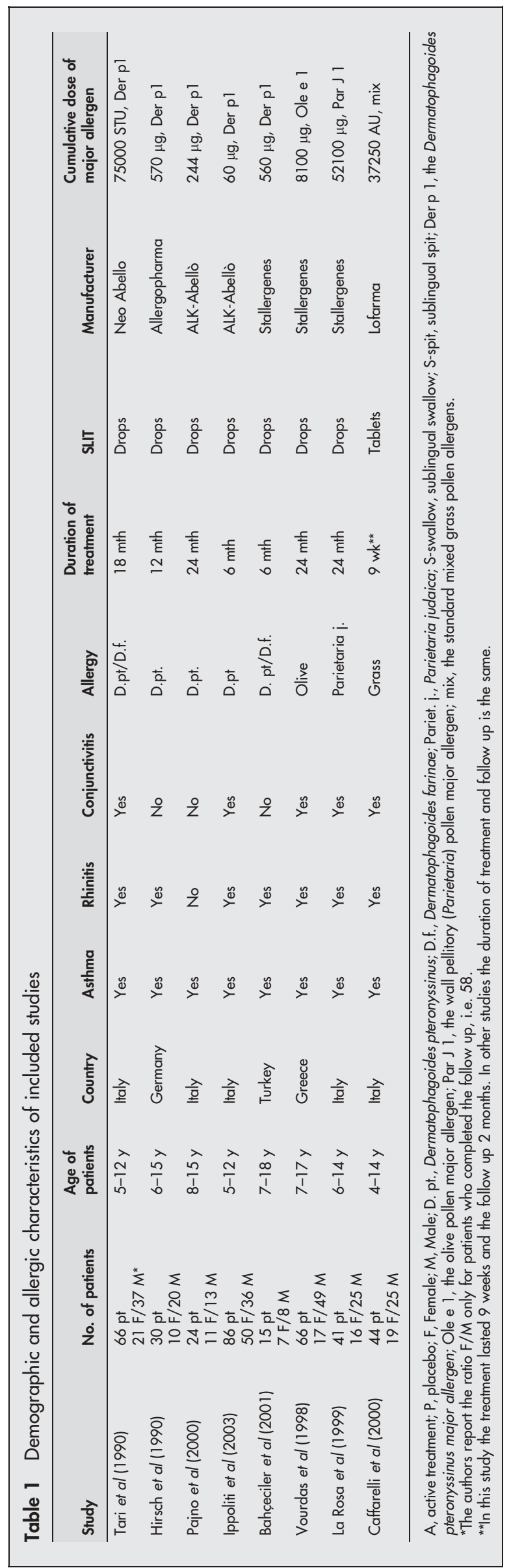

- Hand searching of the last two year' indexes of: Allergy, Annals of Allergy, Asthma and Immunology, Clinical and Experimental Allergy, Pediatric Allergy and Immunology, The Journal of Allergy and Clinical Immunology, Archives of Disease in Childhood, Pediatrics, and The Journal of Pediatrics.

- The archives of some SLIT producers (Alk-Abellò, Anallergo, Bracco, Lofarma, Stallergenes).

As first screening, only abstracts were reviewed; if insufficient, the analysis was extended to the full text.

\section{Selection of studies and quality assessment}

Inclusion criteria

Eligible studies had to fulfil as a first step the following points:

- Be based only on commercial extracts of inhalant allergens (HDM, pollens, pets' epithelia, moulds) administered through the sublingual route (swallow or spit).

- Include patients with respiratory symptoms (asthma, rhinitis, rhinoconjunctivitis).

- Include only children (age range 0-18 years) or, in the case of a mixed paediatric/adult population, the results for the paediatric subjects could be extracted.

- Be based on clinical evaluations (symptom and drug scores).

- Be published in full text.

- Be randomised and run according to a double blind (and double dummy if necessary) design.

- The control group was treated with placebo, SIT administered by routes other than the sublingual one, or drugs.

\section{Exclusion criteria}

Studies were excluded if the drop out during follow up was equal or more than $20 \%$ of randomised patients. ${ }^{13}$

\section{Definition of the outcomes}

At least one of the following clinical outcomes had to have been studied:

- Asthma and/or rhinoconjunctivitis symptoms (assessed by means of a scoring system).

- Intake of rescue and preventive drugs (assessed by means of a scoring system).

A majority of the four reviewers decided the inclusion of each study in this review, after an independent evaluation.

\section{Methodological quality of the included studies}

The methodological quality of the included studies was evaluated according to the criteria given by the EvidenceBased Medicine Working Group. ${ }^{13}$ For every paper the following were analysed: the randomisation process; the efficacy of randomisation (through analysis of the "classical" table 1 of any RCT, where authors usually compare sex, economic status, age, and other specific characteristics); sample size calculation; clear definition of end points; drop outs-those lost during follow up; compliance; intention to treat analysis; placebo concealment; and run in. See table 2 for specific details on each paper. Overall the methodological quality of the studies was not very good. For example, only one $^{15}$ had a priori sample size calculation, and only three studies out of eight clearly stated the methodology of randomisation. On the other hand, all the primary end points were well defined and were decided a priori, such as the plan for statistical analysis. 
Table 2 Methodological characteristics of included studies

\begin{tabular}{|c|c|c|c|c|c|c|c|c|c|}
\hline Study & $\begin{array}{l}\text { Randomisation } \\
\text { process }\end{array}$ & $\begin{array}{l}\text { Assessment } \\
\text { of efficacy of } \\
\text { randomisation† }\end{array}$ & $\begin{array}{l}\text { Sample size } \\
\text { calculation }\end{array}$ & $\begin{array}{l}\text { Clear } \\
\text { definition of } \\
\text { end points }\end{array}$ & $\begin{array}{l}\text { Drop out } \\
\text { or lost } \\
\text { during } \\
\text { follow up }\end{array}$ & Compliance & $\begin{array}{l}\text { Intention } \\
\text { to treat } \\
\text { analysis }\end{array}$ & $\begin{array}{l}\text { Placebo } \\
\text { concealment }\end{array}$ & Run in \\
\hline $\begin{array}{l}\text { Tari et al } \\
\text { (1990) }\end{array}$ & NR & No & No & Yes & $\begin{array}{l}8 / 66 \\
(12 \%)\end{array}$ & NR & Yes & Yes & No \\
\hline $\begin{array}{l}\text { Hirsh et al } \\
\text { (1990) }\end{array}$ & $\begin{array}{l}\text { Code provided by } \\
\text { manufacturer }\end{array}$ & Yes & Yes & Yes & None & $83 \%$ & Yes & Yes & Yes \\
\hline $\begin{array}{l}\text { Pajno et al } \\
(2000)\end{array}$ & Keyed code & Yes & No & Yes & $\begin{array}{l}3 / 24 \\
(12.5 \%)\end{array}$ & NR & Yes & Yes & Yes \\
\hline $\begin{array}{l}\text { Bahçeciler et al } \\
\text { (2001) }\end{array}$ & NR & Yes & No & Yes & None & NR & Yes & Yes & Yes \\
\hline $\begin{array}{l}\text { Ippoliti et al } \\
\text { (2003) }\end{array}$ & NR & Yes & No & Yes & None* & Good* & Yes* & Yes & Yes \\
\hline $\begin{array}{l}\text { Vourdas et al } \\
\text { (1998) }\end{array}$ & NR & Yes & No & Yes & $\begin{array}{l}2 / 66 \\
(3 \%)\end{array}$ & NR & No & Yes & No \\
\hline $\begin{array}{l}\text { La Rosa et al } \\
\text { (1999) }\end{array}$ & NR & Yes & No & Yes & $\begin{array}{l}8 / 41 \\
(19.5 \%)\end{array}$ & $98 \%$ & No & Yes & No \\
\hline $\begin{array}{l}\text { Caffarelli et al } \\
(2000)\end{array}$ & PC generated list & Yes & No & Yes & $\begin{array}{l}4 / 44 \\
(8.4 \%)\end{array}$ & "Very good" & Yes & Yes & No \\
\hline
\end{tabular}

NR, not reported.

†Dates derived by "classical" table 1 of respective papers where demographic and other specific items are usually compared in both groups.

*This information was given directly by the authors.

\section{RESULTS}

A total of 505 papers were examined. One paper could not be found as full text and was therefore excluded. ${ }^{14}$ However, no review or original study subsequently published on this subject has ever mentioned this paper. No study was excluded because of the drop out during follow up being $\geqslant 20 \%$ of randomised patients. In order not to lose any papers the bibliographic research was conducted without any specific limit; all 505 papers described criteria of selection and inclusion . Eight papers ${ }^{11}{ }^{12}{ }^{15-20}$ fulfilled the selection and inclusion criteria. In all of them the comparison was made against placebo. No studies comparing SLIT to immunotherapy administered by other routes or to drugs were found in children. Further details of the search strategies and excluded papers can be obtained from the authors on request.

Tables 1-3 summarise demographic, allergic, and methodological characteristics of the included studies.

\section{Description of the results of each clinical study Studies on HDM allergy}

Tari et al, $1990^{12}$

In the active group the weekly score significantly decreased from 10 to 6 for asthmatic symptoms (equivalent to 40\%) and from 14 to 8 for rhinitis symptoms (equivalent to $43 \%$ ). No significant improvement of the conjunctival symptoms score was detected. No significant improvement in the placebo group was observed for any of the above parameters. On average, the percentage of patients in the active group experiencing a reduction of at least $20 \%$ of the intake of drugs was $40 \%$ higher than in the placebo group.

Hirsch et al, $1997^{15}$

The daily score for asthmatic symptoms showed a significant reduction in the active treated patients; the relative improvement at the end of the study seems remarkable $(80 \%)$, but the difference in absolute value was only -0.29 points/day. No significant improvement in the placebo group was observed and the difference between the groups was significant at the end of the study. No differences were registered between groups in clinical improvement based on the subjective assessment, or in drug consumption. The score of rhinitis symptoms did not differ significantly either within or between groups.

Pajno et al, $2000^{18}$

In the active group the monthly score for nocturnal asthmatic symptoms significantly decreased by $57.1 \%$, going from an average score of 14 to 6 . No significant improvement in the placebo group was observed. At the end of the treatment, the difference between placebo group score (13.2) and active group score (6) was significant. The monthly number of asthma episodes significantly decreased from 1.73 to 0.68 (that is, $-60.7 \%$, in the active group), and from 1.6 to 1.3 (that is, $-18.7 \%$, in the placebo group). At the end of the treatment, the difference between placebo group and active group was significant. In the active group the annual drug

Table 3 Other methodological characteristics of included studies

\begin{tabular}{llllll}
\hline & $\begin{array}{l}\text { Environmental } \\
\text { preventive } \\
\text { measure } \\
\text { against mites }\end{array}$ & $\begin{array}{l}\text { Mono multi- } \\
\text { sensitisation }\end{array}$ & $\begin{array}{l}\text { Clear definition of } \\
\text { asthma/rhinitis/ } \\
\text { conjunctivitis }\end{array}$ & $\begin{array}{l}\text { Clear definition } \\
\text { of scoring system } \\
\text { for symptoms }\end{array}$ & $\begin{array}{l}\text { Clear definition of } \\
\text { scoring system } \\
\text { for drug use }\end{array}$ \\
\hline Tari et al (1990) & Yes & NR & No & Yes & No \\
Hirsh et al (1990) & Yes & Multi & Yes & Yes & No \\
$\begin{array}{l}\text { Pajno et al (2000) } \\
\text { Bahçeciler et al }\end{array}$ & Yes & Meso & Yes & Yes & Yes \\
(2001) & Mono & Yes & Yes & Yes \\
lppoliti et al (2003) & NR & Mono & Yes & Yes & Yes \\
Vourdas et al (1998) & - & Multi & Yes & Yes & Yes \\
La Rosa et al (1999) & - & Mono & No & Yes & Yes \\
Caffarelli et al & - & Mono & No & & Yes \\
(2000) & & & & & \\
\hline
\end{tabular}


score significantly changed from 259.68 to 82.68 , with a $-68.2 \%$ reduction significantly higher than in the placebo group $(-30.2 \%)$. The four month average score of the patient's subjective assessment significantly changed only in the active group, from 5.1 to 2.5 , with a $49 \%$ improvement.

Bahçeciler et al, $2001^{19}$

In the active group the daily score for asthmatic symptoms significantly decreased from 0.64 to 0.30 , with a $53 \%$ relative reduction. There was also a significant reduction from 0.17 to 0.03 of the score for $\beta_{2}$ agonists but no difference in the use of inhaled steroids and in patients' subjective assessment of the clinical outcome. More clinically relevant, the number of acute asthma episodes at the end of the treatment period was 3 in the active group compared to 30 in the placebo group. Differences within the active group of the score for rhinitis symptoms and subjective assessment were not significant, whereas the use of nasal steroids was statistically significant (daily average score changed from 3 to 1). No significant difference for any of the above parameters was observed in the placebo group. Finally, there was no statically significant difference between the two groups in the analysis of the daily asthma and rhinitis scores at the end of the study.

Ippoliti et al, $2003^{20}$

In the active group there was a significant, and clinically relevant, decrease in asthma scores from 3.28 (daily mean of run-in period) at baseline to 1.28 (daily mean of six months of therapy) with a $61 \%$ relative reduction. Daily rhinitis score significantly decreased (from 0.84 to 0.39 ) with a $54 \%$ relative reduction, and $\mathrm{FEV}_{1}$ significantly improved (from $83.4 \%$ to $92.6 \%$ ). No significant difference for any of the above parameters was observed in the placebo group.

\section{Studies on other allergens}

Vourdas et al, $1998^{16}$

In this trial the outcomes were reported as daily mean symptom scores at the peak of the pollen season in both years investigated. The differences between the scores of asthmatic symptoms at the peak of the first (active $=0.15$, placebo $=0.3$ ) and the second pollen season (active $=0.04$, placebo $=0.28)$ were significant. A significant difference was observed for conjunctival symptom scores (active $=0.03$, placebo $=0.22$ ) only at the pollen peak during the second year. No significant difference was reported for rhinitis symptom scores. No difference in drug consumption or subjective assessment for the same period was detected.

La Rosa et al, $1999^{17}$

No significant difference was reported between the active and the placebo group with reference to the score of rhinitis symptoms during the observation period. There was a significant difference in the active group compared to placebo in the proportion of patients with a clinical improvement of at least $30 \%$ in rhinitis symptoms (87.5\% $v 47.5 \%)$. A significant difference in active group compared to placebo was also observed for the daily score of drugs for rhinitis, but only during the first week of the first pollen season $(0.38 \mathrm{v}$ $0.95)$.

\section{Caffarelli et al, $2000^{11}$}

A significant difference for the weekly score for asthmatic symptoms between the active (2.7) and the placebo group (4.6) was reported. This difference corresponds to a saving of 0.27 points/day for the active group. However, no significant saving of drugs was reported. No differences were seen in the weekly score for rhinitis and conjunctivitis symptoms.

\section{DISCUSSION}

The increase of both the debate and the number of clinical studies on SLIT led us to perform a systematic review on the efficacy of this form of immunotherapy in children.

The immunological aspects of SLIT are not still clear, especially in comparison with injection specific immunotherapy. ${ }^{21-24}$ Many studies on SLIT have focused on possible decrease of serum IgE or/and increase of IgGl and IgG4, but these changes were not constant and reproducible. ${ }^{25}$ Recently SLIT has been proved to reduce intercellular adhesion molecule 1 expression on nasal epithelial cells and to decrease methacholine responsiveness. ${ }^{28}$

The ARIA document ${ }^{6}$ supports the use of SLIT in seasonal allergic rhinitis in children. We cannot agree, as of three studies mentioned in this document to support its use in this indication, only one $\mathrm{e}^{16}$ dealt with children showing no significant differences for rhinitis symptoms, whereas the other $\mathrm{two}^{29} \mathrm{in}^{30}$ investigated a mixed population (adults and children), but the outcomes regarding the paediatric sample cannot be extrapolated.

Moreover, in the studies we reviewed, the number of patients with a single allergen is low, the overall efficacy is clinically irrelevant, and the methodological validity is poor. According to our results the judgement on the efficacy of SLIT in seasonal respiratory allergies in children should wait until proper studies are available.

Regarding the clinical efficacy of SLIT in asthma due to HDM, in all five studies we reviewed, the improvement of the before and after asthmatic score was statistically significant only in the active group; in three ${ }^{12} 1820$ it was also clinically relevant. No relation among relevance of clinical results, duration of treatment, and/or degree cumulative dose, was observed. Four of five studies performed environmental preventive measures against HDM; the observed efficacy of SLIT seems to be additional to these preventive measures.

With reference to rhinitis due to HDM, the studies we reviewed showed a significant and clinically relevant effect in two $\operatorname{cases}^{12} 20$ and no effects in the other two. ${ }^{15}$ For rhinoconjunctivitis due to HDM, the judgement is not clear and still pending on new data. It is difficult to understand why, in children, SLIT improves asthmatic symptoms, while this benefit is not so clearly evident for rhinitis.

In conclusion, the use of SLIT can be recommended in children of at least 4 years of age suffering from mild to moderate persistent asthma due to monosensitisation to HDM or having further sensitisation without clinical relevance. The efficacy on symptoms and on drug consumption can be defined as low to moderate and probably considered additive to the efficacy achievable with the environmental avoidance measures.

However, the following need to be explored: a comparison of SLIT with pharmacological prevention, an economic costbenefit analysis, optimal dose standardisation and duration of treatment, the prevention of new sensitisation, and the real improvement of quality of life of allergic children.

\section{ACKNOWLEDGEMENTS}

Stefano Miceli Sopo, Giulia Zorzi, and Salvatore Tripodi are members of the Associazione pediatri Pneumologi Allergologi Laziali (Lazial association of pediatric allergist and pneumologist) (ApPAL). The authors thank all other members of ApPAL for suggestions and constructive criticisms to this paper.

\section{Authors' affiliations}

S Miceli Sopo, M Macchiaiolo, G Zorzi, Department of Pediatric Science, Università Cattolica del Sacro Cuore, Rome, Italy S Tripodi, Pediatric Department, Pediatric Allergology Unit, Ospedale Sandro Pertini, Rome, Italy 


\section{REFERENCES}

1 Douglass J, O'Hehir R. Specific allergen immunotherapy: time for alternatives? Clin Exp Allergy 2002;32:1-3.

2 Andre C, Vatrinet C, Galvain S, et al. Safety of sublingual-swallow immunotherapy in children and adults. Int Arch Allergy Immunol 2000;121:229-34.

3 Di Rienzo V, Pagani A, Parmiani S, et al. Post-marketing surveillance study on the safety of sublingual immunotherapy in pediatric patients. Allergy 1999;54:1110-13.

4 WHO Position Paper. Allergen immunotherapy: therapeutic vaccines for allergic diseases. Allergy 1998;53(44 suppl): 1-42.

5 Frew AJ, Smith HE. Sublingual immunotherapy. J Allergy Clin Immunol $2001 ; 107: 441-4$

6 Bousquet and the ARIA Workshop Group. Allergic rhinitis and its impact on asthma. J Allergy Clin Immunol 2001;108:S147-276.

7 Kagi MK, Wuthrich B. Different methods of local allergen-specific immunotherapy. Allergy 2002;57:379-88.

8 Passalacqua G, Canonica GW. Allergen-specific sublingual immunotherapy for respiratory allergy. BioDrugs 2001;15:509-19.

9 Abramson MJ, Puy RM, Weiner JM. Allergen immunotherapy for asthma (Cochrane Review). The Cochrane Library, Issue 3. Oxford: Update Software 2002.

10 Wilson DR, Torres Lima M, Durham SR. Sublingual immunotherapy for allergic rhinitis (Cochrane Review). The Cochrane Library, Issue 2. Oxford: Update Software, 2003.

11 Caffarelli C, Sensi LG, Marcucci F, et al. Preseasonal local allergoid immunotherapy to grass pollen in children: a double-blind, placebocontrolled, randomized trial. Allergy 2000;55:1142-7.

12 Tari MG, Mancino M, Monti G. Efficacy of sublingual immunotherapy in patients with rhinitis and asthma due to house dust mite. A double-blind study. Allergol Immunopathol 1990;18:277-84.

13 Guyatt G, Rennie D, eds. Users' guides to the medical literature. A manual for evidence-based medical practice. The Evidence-Based Medicine Working Group, JAMA \& Archives Journal, American Medical Association, 2002.

14 Moshkevich VS, Esenzhanova GM. Local specific treatment of dust-induced bronchial asthma. Ter Arkh 1982;54:72-6.

15 Hirsch T, Sahn M, Leupold W. Double-blind placebo-controlled study of sublingual immunotherapy with house dust mite extract (D.pt.) in children. Pediatr Allergy Immunol 1997;8:21-7.

16 Vourdas D, Syrigou E, Potamianou P, et al. Double-blind, placebo-controlled evaluation of sublingual immunotherapy with standardized olive pollen extract in pediatric patients with allergic rhinoconjunctivitis and mild asthma due to olive pollen sensitization. Allergy 1998;53:662-72.
17 La Rosa M, Ranno C, Andre C, et al. Double-blind placebo-controlled evaluation of sublingual-swallow immunotherapy with standardized Parietaria judaica extract in children with allergic rhinoconjunctivitis. J Allergy Clin Immunol 1999; 104(2 pt 1):425-32.

18 Pajno GB, Morabito L, Barberio G, et al. Clinical and immunologic effects of long-term sublingual immunotherapy in asthmatic children sensitized to mites: a double-blind, placebo-controlled study. Allergy 2000;55:842-9.

19 Bahceciler NN, Isik U, Barlan IB, et al. Efficacy of sublingual immunotherapy in children with asthma and rhinitis: a double-blind, placebo-controlled study. Pediatr Pulmonol 2001;32:49-55.

20 Ippoliti F, De Santis W, Volterrani A, et al. Immunomodulation during sublingual therapy in allergic children. Pediatr Allergy Immunol 2003; 14:216-21.

21 Lichtenstein LM, Ishizaka K, Norman PS, et al. IgE antibody measurements in ragweed hay fever. Relationship to clinical severity and the results of immunotherapy. J Clin Invest 1973;52:472-82.

22 Creticos PS, Adkinson NF Jr, Kagey-Sobotka A, et al. Nasal challenge with ragweed pollen in hay fever patients. J Clin Invest 1985;76:2247-53.

23 Secrist H, Dekruyff RH, Umetsu DT. Interleukin 4 production by CD $4+T$ cells from allergic individuals is modulated by antigen concentrations and antigen presenting cell type. J Exp Med 1995;181:1081-9.

24 Varney VA, Hamid QA, Gaga M. Influence of grass pollen immunotherapy on cellular infiltration and cytokine mRNA expression during late phase cutaneous response. J Clin Invest 1993;92:644-50

25 Fanta C, Bohle B, Hirt W, et al. Systemic immunological changes induced by administration of grass pollen allergens via the oral mucosa during sublingual immunotherapy. Int Arch Allergy Appl Immunol 1999;120:218-24.

26 Passalacqua G, Albano M, Fregonese L, et al. Randomised controlled trial of local allergoid immunotherapy on allergic inflammation in mite induced rhinoconjunctivitis. Lancet 1998;351:629-32.

27 Passalacqua G, Albano M, Riccio AM, et al. Clinical and immunological effects of a rush sublingual immunotherapy to parietaria species: a double blind placebo controlled trial. J Allergy Clin Immunol 1999;104:964-8.

28 Silvestri M, Spallarossa D, Battistini E, et al. Changes in inflammatory and clinical parameters and in bronchial hyperreactivity asthmatic children sensitized to house dust mites following sublingual immunotherapy. J Invest Allergol Clin Immunol 2002; 12:52-9.

29 Sabbah A, Hassoun S, Le Sellin J, et al. A double-blind, placebo-controlled trial by the sublingual route of immunotherapy with a standardized grass pollen extract. Allergy 1994;49:309-13.

30 Clavel R, Bousquet J, Andre C. Clinical efficacy of sublingual-swallow immunotherapy: a double-blind, placebo-controlled trial of a standardized five-grass-pollen extract in rhinitis. Allergy 1998;53:493-8.

\section{IMAGES IN PAEDIATRICS}

\section{Bovine insulin therapy and lipohypertrophy}

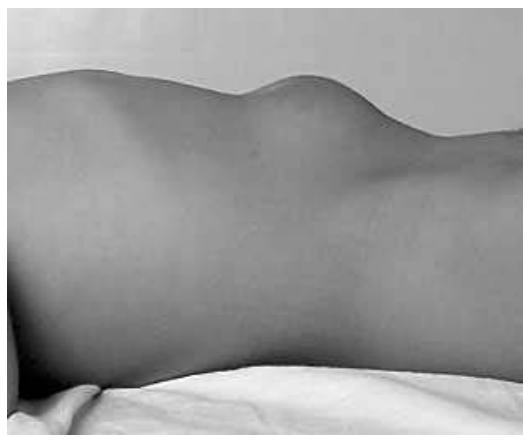

n 8 year old boy with a two year history of type 1 diabetes mellitus, treated with purified
bovine insulin, developed lipohypertrophy at the site of insulin injection (see fig).
Lipohypertrophy is a relatively more common complication than lipoatrophy with
purified insulin treatment. It should be specifically looked for before increasing insulin dose
whenever a previously euglycaemic patient presents with uncontrolled blood glucose. Good
glycaemic control can be achieved by just rotating the injection site in the uninvolved area. The
lipohypertrophy is linked to the local lipogenic action of insulin and is more likely related to the
frequency of injections at a given site and purity of insulin than to the dose or species of insulin.
When purified insulin preparations were not available, lipoatrophy at the injection site was
relatively common, and was attributed to the impurities in the preparation, leading to immune
complex deposition and subsequent atrophy.

S Mahadevan, S K Bhadada, P Velayutham, A Bhansali Postgraduate Institute of Medical Education and Research; anilbhansali_endocrine@rediffmail.com 